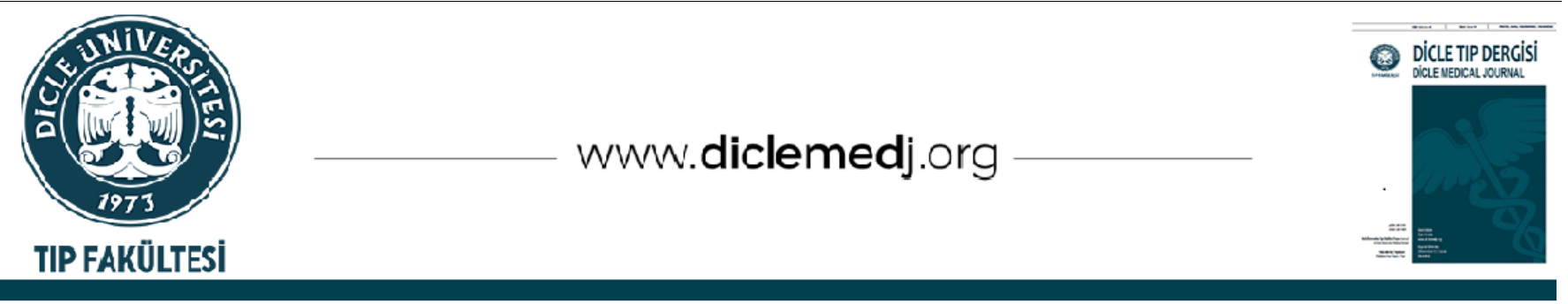

Özgün Araştırma / Original Article

\title{
Morbid Obez Hastalarda Obezite Medikal Tedavi Başarısı ile Başlangıç HbA1c Düzeyi İlişkisi
}

\author{
Mehmet Güven ${ }^{1} 1$ \\ 1 Şırnak Devlet Hastanesi, Endokrinoloji ve Metabolizma Hastalıkları Kliniği, Şırnak, Türkiye
}

Geliş: 23.03.2021; Revizyon: 27.04.2021; Kabul Tarihi: 27.04.2021

Öz

Giriş: Komorbiditelerin azaltılmasına yönelik başlangıçta \%5-10 kilo kaybının obezitede önemli klinik yararları gösterilmiştir. Bu çalışmada, yeni tanı morbid obezlerde üç aylık yaşam tarzı değişikliği ve farmakolojik tedavinin sonunda etkili kilo kaybının bazal klinik parametreler ile öngörülüp öngörülemeyeceği araştırıldı.

Yöntemler: Retrospesifik olarak yapılan bu çalışmada, daha önce bilinen komorbid hastalığı olmayan, 58 yeni tanı morbid obez hastanın üç aylık yaşam tarzı değişikliği ve farmakolojik tedavi sonrasında antropometrik ölçümler, kan basıncl, lipit profili, açlık glukoz ve insülin düzeyi, karaciğer enzimleri ve HBA1c düzeyinin tedavi öncesi ve tedavi sonrasındaki sonuçları karşılaştırıldı. Başlangıca göre kilo kaybı oranları hesaplanıp \%5' in altında (grup 1, $\mathrm{n}=13$ ), \%510 (grup 2, n = 24), \%10' un üstünde (grup 3, n = 21) kilo kaybedenler olarak gruplandırıldı.

Bulgular: Başlangıç vücut-kitle indeksi medyan $42.78 \mathrm{~kg} / \mathrm{m}^{2}$ iken üç ay sonunda medyan $39.96 \mathrm{~kg} / \mathrm{m}^{2}$ ye gerilemişti. Medyan kilo kaybı $9 \mathrm{~kg}$ (çeyreklerarası aralık, 6-13 kg) bulundu. Ortalama bazal HBA1c düzeyi, grup 3' te en yüksek izlendi. Bazal ortalama HBA1c düzeyi ile kilo kaybı arasında Pearson korelasyon analizine göre pozitif yönde anlamlı korelasyon izlendi (rho: 0.468, p < 0.001). \%10' dan fazla kilo kaybını öngörmek için bazal klinik ve laboratuar parametreleri ile multivaryant logistik regresyon analizi oluşturulduğunda sadece bazal HBA1c düzeyi anlamlı bulundu (Odds ratio $=5.2$ [\%95 Güven aralığı 1.03-26.15], $\mathrm{p}<0.05$ ).

Sonuç: Yeni tanı morbid obezlerde üç aylık yaşam tarzı değişikliği ile beraber farmakolojik tedavi verildiğinde başlangıç HBA1c düzeyi yüksek olanlarda daha etkili kilo kaybının olabileceği ön görülebilir.

Anahtar kelimeler: obezite, morbid obezite, kilo kaybı, farmakolojik tedavi, HBA1c

DOI: $10.5798 /$ dicletip.944394

Yazışma Adresi / Correspondence: Mehmet Güven, Şırnak Devlet Hastanesi, Endokrinoloji ve Metabolizma Hastalıkları Kliniği, Şırnak, Türkiye e-mail: dr.mguven@gmail.com 


\title{
Association of Initial HbA1c Level with Obesity Medical Treatment Success in Morbidly Obese Patients
}

\begin{abstract}
Objective: Significant clinical benefits of 5-10\% weight loss in obesity have been shown at the beginning to reduce comorbidities. In this study, it was investigated whether effective weight loss at the end of three months of lifestyle change and pharmacological treatment in newly diagnosed morbidly obese patients could be predicted by basal clinical parameters.
\end{abstract}

Methods: In this retrospecific study, anthropometric measurements, blood pressure, lipid profile, fasting glucose and insulin levels, liver enzymes and HBA1c levels were determined before treatment after three-month lifestyle change and pharmacological treatment of 58 newly diagnosed morbid obese patients without previously known comorbid diseases and the results after treatment were compared. Weight loss rates were calculated according to baseline and were grouped as <5\% (group 1, $\mathrm{n}=13$ ), 5-10\% (group 2, $\mathrm{n}=24$ ), and $\geq 10 \%$ (group 3, $\mathrm{n}=21$ ).

Results: While the median initial body-mass index was $42.78 \mathrm{~kg} / \mathrm{m}^{2}$, it had regressed to $39.96 \mathrm{~kg} / \mathrm{m}^{2}$ at the end of three months. Median weight loss was $9 \mathrm{~kg}$ (interquartile range, 6-13 kg). The mean basal HBA1c level was the highest in group 3. A positive significant correlation was observed between the basal mean HBA1c level and weight loss according to Pearson correlation analysis (rho: $0.468, \mathrm{p}<0.001$ ). When multivariate logistic regression analysis was created with baseline clinical and laboratory parameters to predict more than $10 \%$ weight loss, only the basal HBA1c level was found to be significant (Odds ratio $=5.2$ [95\% confidence interval 1.03-26.15], p <0.05).

Conclusions: When pharmacological treatment is given together with a three-month lifestyle change in newly diagnosed morbid obese patients, it can be predicted that more effective weight loss may occur in those with a high initial HBA1c level.

Keywords: obesity, morbid obesity, weight loss, pharmacological treatment, HBA1c.

\section{GíRiş}

Obezite, dünyada prevelansı gün geçtikçe artan küresel bir epidemiye neden olan kronik bir hastalıktır. Türkiye' de 2010 yılında yapılan TURDEP-II çalışmasında 20 yaş üstü bireylerde obezite prevelansı \%30,1 olarak bulunmuştur ${ }^{1}$. Obezite, diyabetes mellitus, hipertansiyon, dislipidemi, koroner arter hastalığl, inme, uyku apnesi ve kanser gibi birçok hastalıkla ilişkili olması bakımından önemli bir morbidite ve mortalite nedenidir.

Obezitenin tedavisi, komorbiditeleri ve ilgili maliyetleri azaltmak ve hastaların yaşam kalitesini artırmak açısından çok önemlidir. Vücut ağırlığının sadece \%5 kaybı gibi küçük kilo kayıpları bile sağlığa önemli yararlar sağlayabilmektedir ${ }^{2}$. Yalnızca yaşam tarzı değişiklikleri ile vücut ağırlığının \%5 ile 7' sini kaybetmek olasıdır ancak genellikle bu yaşam tarzı değisşikliklerinin uzun süre sürdürülmesi zordur. Yapılan çalışmalarda yaşam tarzı değişikliği ile birlikte farmakolojik tedavinin $\% 5$ ila \%10 kilo kaybı sağlaması çok iyi bir yanıt ve \%10' u aşan kilo kaybı ise mükemmel bir yanıt olarak kabul edilir ${ }^{3}$. Avrupa Yetişkin Obezite Kılavuzunda üç ay içinde $\% 5$ kilo kaybı sağlanamaması durumunda obezite için verilen farmakolojik tedavinin kesilmesi önerilmektedir 4 .

Kilo verme yaklaşımları, psikososyal faktörler, motivasyon seviyeleri, genetik faktörler ve mevcut destek tedavileri dahil olmak üzere birçok değiştirilebilir ve değiştirilemez faktörler başarılı kilo kaybına katkıda bulunabilir ${ }^{5-7}$. Bu nedenle obez hastalarda etkili kilo kaybının gerçekleşebileceğini önceden öngörebilmek neredeyse çok zordur. $\mathrm{Bu}$ çalışmamızda önceden bilinen komorbid hastalığı olmayan yeni tanı morbid obez hastalarda yaşam tarzı değişiklikleri ve farmakolojik tedavi başlamadan önce bazal antropometrik ölçümler, kan basıncı ve 
laboratuar verileri ile etkili kilo kaybının öngörülüp öngörülemeyeceğini araştırmayı amaçladık.

\section{YÖNTEMLER}

\section{A. Hasta seçimi ve çalışma dizaynı}

Retrospesifik olarak yapılan bu çalışma, Ocak 2020-Mart 2021 tarihleri arasında yeni tanı morbid obezite nedeniyle Şırnak Devlet Hastanesine başvuran hastaları kapsamaktadır.
Calıșmamıza lokal etik komite tarafından onay verilmiştir (karar no: 2021/2794).

Şırnak Devlet Hastanesine, Ocak 2020-Mart 2021 tarihleri arasında hastane kayıt sisteminden bakılarak, morbid obezite nedeniyle 142 hastanın başvurduğu görüldü. Bunların 84 tanesi uygunluk kriterini karşılamadığından çalışma dışında tutuldu. Çalışma kriterini sağlayan 58 morbid obez hasta çalışmaya alındı (Şekil 1).

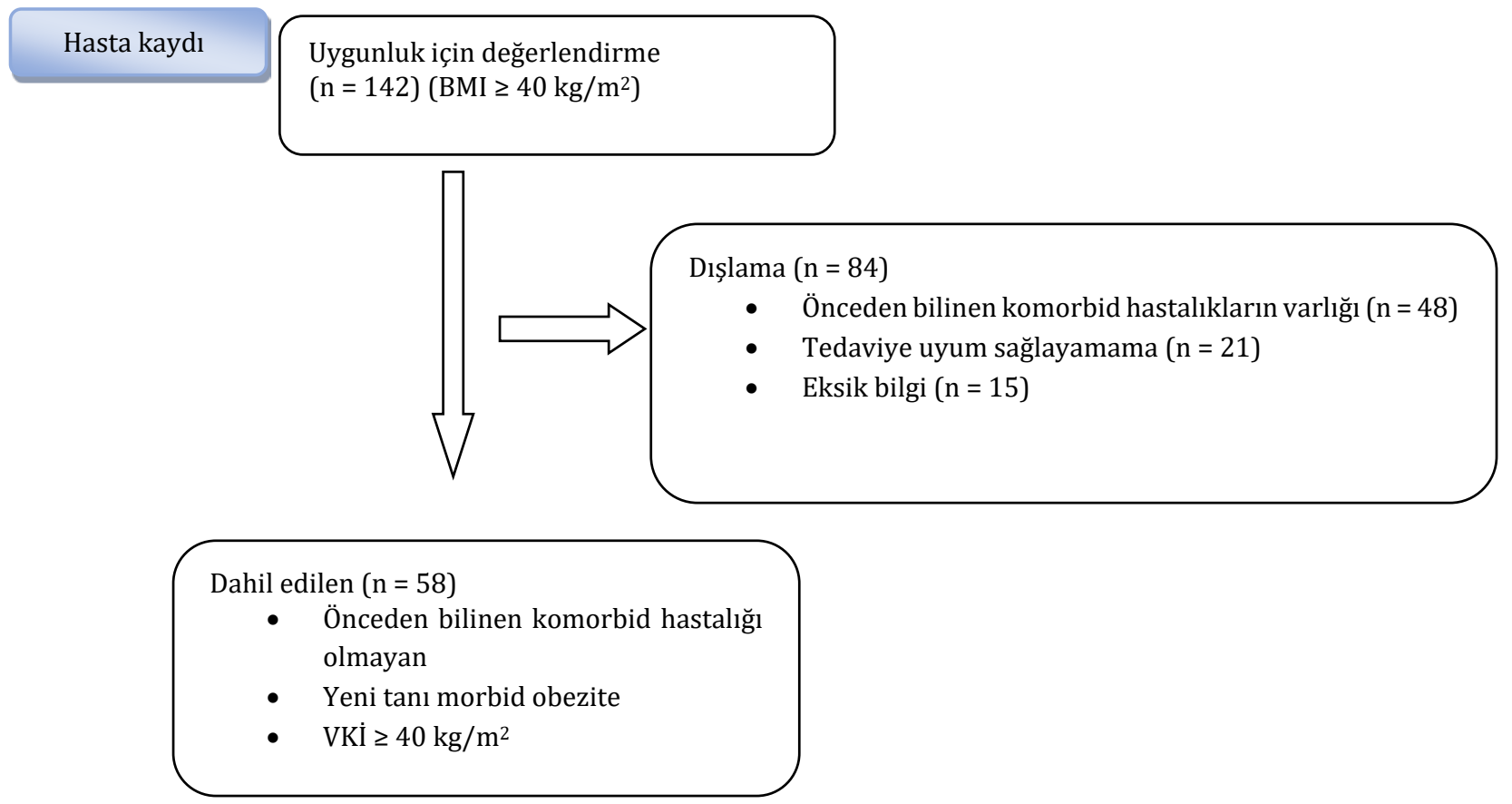

Şekil 1. Çalışmanın akış çizelgesi

Hastaların çalışma için planlanan tüm klinik bilgileri hasta dosya sisteminden geriye dönük bakılarak kaydedilmiști.

\section{B. Uygunluk kriteri}

Çalışmamıza morbid obezite ile birlikte daha önce bilinen komorbid hastalıkları (diyabetes mellius, esansiyel hipertansiyon, kardiyovasküler hastalık gibi) ve sekonder obezitesi (hipotiroidi, kronik inhaler, oral veya transdermal kortikosteroid kullanımı olan hastalar, Cushing sendromu gibi) ile sendromik obeziteye sahip (Prader Wili Sendromu,
Alström Sendromu, Down sendromu gibi) hastalar dahil edilmemiştir. Daha önce obezite nedeniyle yaşam tarzı değissikliği veya farmakolojik tedavi alan hastalar da çalışma dışında tutulmuştur. Çalışma uygunluk kriterlerini sağlayıp morbid obezite nedeniyle farmakolojik tedavi verildikten sonra bu tedavi şeklini üç ay boyunca devam ettiremeyen veya dosya kayıt sisteminde çalışma için gerekli bilgileri eksik olan hastalar da çalışma dıșında tutulmuştu. Bunun haricinde 18 yaş ve üstü morbid obezite nedeniyle ilk defa başvuran, 
daha önce bilinen komorbid hastalığı olmayan ve üç aylık farmakolojik tedaviyi devam ettirip, klinik takipleri dosya kayıt sisteminde eksiksiz olan hastalar çalışmaya alınmıştır.

\section{Antropometrik ölçümler ile kan basıncı ölçümü}

Morbid obezite nedeniyle başvuran hastalardan tecrübeli sağlık personeli tarafından sabah aç karınla ayakkabıları çıkarılıp üzerinde ince kıyafetler olacak şekilde kilo ve boy ölçümü yapıldl.

Kilo ve boy ölçümü için Freely marka mekanik boy ve kilo baskülü kullanıldı. Baskülün kalibrasyonu Temmuz 2021 tarihine kadar geçerli olacak şekilde kontrol edilip onaylanmıştı.

Bel çevresi, süperior iliak krest ile son kaburganın alt kenarı arasındaki yatay düzlemde normal bir ekspirasyonun sonunda, karın etrafına yatay olarak yerleştirilmiş ve cildi sıkıștırmayan bir ölçüm bandı kullanılarak ölçülmüştü.

Kan basıncl, hastanın $10 \mathrm{dk}$ dinlenmesinden sonra oturur pozisyonda üst koldan Erka marka tansiyon manşonu kullanılarak ölçülmüştü.

\section{Laboratuar parametreleri}

Hastalardan 8-12 saat açlı̆ı takiben sabah 08.00 - 09.00 civarında aç karınla açlık glukoz, açlık insülin, HBA1c (Hemoglobin A1c), AST (Aspartat Aminotransferaz), ALT (Alanin Aminotransferaz), Trigliserit, LDL (Düşük yoğunluklu lipoprotein), HDL (Yüksek yoğunluklu lipoprotein) düzeyi için kan örnekleri alındı.

Aynı kan örnekleri üç aylık yaşam tarzı değişikliği ve farmakolojik tedaviden sonra aynı prosedürlerle kontrol amaçlı tekrar alınmıştı.

Alınan kan sonuçları aynı günde sonuçlanmıştı. Tüm bu kan örneklerinin sonuçları retrospesifik olarak hasta kayıt dosyalarından kaydedildi.

\section{F. Obezite nedeni olan diğer patolojilerin dışlanma prosedürü}

Polikliniğe ilk başvuru esnasında tiroid hormonal bozukluklarını dışlamak için TSH düzeyi istenmişti. TSH düzeyi çalışmaya aldığımız morbid obezlerde ötiroid seviyesindeydi.

Hiperkortizolizmin klinik şüphesini taşımayan morbid obezlerde Cushing sendromu araştırılması yapılmamıştı. Klinik şüphe taşıyanlara (cilt atrofisi, aydede yüzü, spontan ekimozlar, proksimal miyopati, geniş mor strialar gibi) ise $1 \mathrm{mg}$ deksametazon supresyon testi uygulanmıştı. Hiçbir hastada Cushing sendromu tanısı konulmamıştı.

\section{E. Tanımlamalar}

İnsülin direnci olarak HOMA-IR (İnsülin direnci için homeostatik model değerlendirmesi) metodu kullanıldı. HOMA-IR, açlık glukoz $(\mathrm{mg} / \mathrm{dL}) \mathrm{x}$ açlık insülin $(\mu \mathrm{U} / \mathrm{mL}) / 405$ olarak hesapland $1^{8}$.

VKİ (vücut-kitle indeksi), kilo' nun (kg), boyun karesine $\left(\mathrm{m}^{2}\right)$ bölünmesiyle hesaplandı $\left(\mathrm{kg} / \mathrm{m}^{2}\right)$.

Morbid obezite ( Klas III obezite) tanısı VKI $\geq 40$ $\mathrm{kg} / \mathrm{m}^{2}$ olmasiyla konuldu ${ }^{9}$.

Açlık plazma glukozu $\geq 126 \mathrm{mg} / \mathrm{dL}$ veya HBA1C $\geq 6.5 \%$ ise Tip 2 diyabetes mellitus tanısı konuldu.

Değişim düzeyi; tedavi öncesi değerden (bazal), üç ay sonraki değerin çıkarılmasıyla hesaplandı.

\section{E. Yaşam tarzı değişikliği ve Farmakolojik tedavi}

Morbid obezitesi olan tüm hastalara, uzman bir diyetisyen tarafından kapsamlı bir yaşam tarzı müdahalesi uygulandı. Diyet, egzersiz ve davranış modifikasyonunun bir kombinasyonu olan yaşam tarzı müdahalesinde düşük kalorili diyet rejimi (günlük ortalama 1200-1500 $\mathrm{kcal} /$ gün) uygulandı. 
Amerikan Klinik Endokrinoloji Derneği insülin direnci olan obez hastalarda metformin kullanımını önermektedir ${ }^{10}$. Amerika Gıda ve İlaç Dairesi (FDA), VKI $\geq 30 \mathrm{~kg} / \mathrm{m}^{2}$ olan obezlerde orlistat kullanımına onay vermiştir ${ }^{11}$. Türkiye' de Sağlık Bakanlığı ise VKİ $\geq 40 \mathrm{~kg} / \mathrm{m}^{2}$ olan morbid obezlerde orlistat kullanımına onay vermiştir. Bu nedenle çalışmaya aldığımız insülin direnci olan VKİ $\geq 40 \mathrm{~kg} / \mathrm{m}^{2}$ olan hastalara kilo verdirici ilaç olarak metformin ve orlistat verilmişti. Çalışmadaki morbid obez hastalara metformin $1000 \mathrm{mg}$ (günde iki kez), orlistat $120 \mathrm{mg}$ (günde üç kez) reçete edilmiști. $\mathrm{Bu}$ ilaçların haricinde hastalara lipit düşürücü tedaviler veya başka ajan ilaç tedavileri uygulanmamıştı. Çalıșmadaki hastaların hiçbirinde kullanılan ilaca ait yan etki gözlenmemişti.

Obezite tedavisinde kilo kaybettiren enjeksiyon tedavi yöntemlerini (eksenatide, liraglutide) hastalar kullanmak istemediklerinden oral tedavi yöntemi seçilmişti.

Farmakolojik tedavi verilen hastalar aylık kontrollere gelip hem biten ilacı tekrar reçete edildi hem de ilacın devamlı kullanıldığı teyid edildi. Tüm hastalar üç aylık süre boyunca kesintisiz olarak yaşam tarzı değişikliği ile farmakolojik tedaviyi devam ettirmişlerdi.

\section{F. Çalışma sonuçları}

Primer sonlanım noktası, üç ay sonunda $\% 10$ ve üstü kilo kaybının bazal klinik parametrelerle olan ilişkisiydi. Sekonder sonlanım noktası ise tedavi öncesi ile üç ay sonraki antropometrik ve klinik parameterlerin değişimiydi.

\section{İstatiksel Analiz}

Veriler, Windows programı için SPSS 22 (IBM, Chicago, IL, ABD) kullanılarak istatistiksel olarak analiz edildi. Sürekli değișkenler medyan (çeyreklerarası aralık [IQR]) ve ortalama (standart sapma [SD]) değerleri olarak sunuldu. Kategorik değişkenler, sayı (n) ve yüzde (\%) olarak sunuldu. Dağılımın normalliği,
Kolmogorov-Smirnov testi kullanılarak değerlendirildi. Normal dağılıma uyan değișkenler, Paired sample T-testi ile normal dağılıma uymayan değisskenler Wilcoxon signed-rank testi ile değerlendirildi. Gruplar arasındaki kategorik değişkenleri incelemek için ki-kare testi kullanıldı. Non-parametrik değişkenler arasındaki korelasyon, Spearman'ın sıralama korelasyon katsayısı ile değerlendirildi.

Üç ayın sonunda başlangıç kilosuna göre kilo kaybı oranları < \%5, \%5-10, > \%10 olarak kategorize edildi. \%10'dan fazla kilo kaybını bağımsız olarak öngörebilmek için tedavi öncesi ortak değişkenler (VKİ, bel çevresi, sistolik ve diyastolik kan basıncl, açlık glukoz, açlık insülin, HOMA-IR, HBA1c, trigliserit, LDL, HDL, AST, ALT, cinsiyet ve yaş) ile univaryant ve multivaryant logistik regresyon analizi oluşturuldu. $\mathrm{p}<0.05$ istatiksel olarak anlamlı kabul edildi.

\section{BULGULAR}

Çalışmaya 11' i erkek (\%19), 47 kadın (\%81) olmak üzere 58 morbid obez hasta alınmıștı. Yaş dağılımı, minumum-maksimum (min-max) 2552 yll olup medyan yaş 37 yll (IQR, 31-45 yll) idi. Tedavi öncesi min-max kilo 90-152 kg bulundu. Açlık plazma glukozu ve HBA1c düzeyine göre değerlendirme yapıldığında, hastaların \%60' inda $(\mathrm{n}=35)$ yeni tanı Tip 2 diyabetes mellitus saptanmıştı.

Üç aylık yaşam tarzı değişikliği ile birlikte farmakolojik tedavi verildiğinde antropometrik ölçümler (kilo, bel çevresi), sistolik ve diyastolik kan basıncı, açlık insülin düzeyi, HOMA-IR, HBA1c düzeyi, ALT, trigliserit ile LDL düzeyi belirgin bir şekilde azalmıştı. Açlık glukozu, AST ve HDL düzeyi ise istatiksel olarak anlamlı bir farklılık göstermemiști. Tedavi başlangıcı ile tedaviden üç ay sonraki değerlerin karşılaştırması ve değişim miktarı Tablo 1' de gösterilmiştir. 
Tablo I: Tedavi öncesi ile tedaviden 3 ay sonraki antropometrik ve klinik parametrelerin karşılaştırılması

\begin{tabular}{|c|c|c|c|c|}
\hline Parametreler & Tedavi öncesi & Tedaviden 3 ay sonra & Değişim & p değeri \\
\hline Boy, cm, IQR & $1.57(1.51-1.65)$ & $1.57(1.51-1.65)$ & 0 & \\
\hline Kilo, kg, IQR & $110(102-120)$ & $100(94-110)$ & $9(6-13)$ & $<0.001 * *$ \\
\hline VKI, $\mathrm{kg} / \mathrm{m}^{2}, \mathrm{IQR}$ & 42.78 (39.97-47.68) & $39.96(36.7-42.7)$ & $3.71(2.32-5.67)$ & $<0.001 * *$ \\
\hline Bel çevresi, cm, IQR & $118.5(112-132.5)$ & $111(106-121)$ & $7(2-10.25)$ & $<0.001 * *$ \\
\hline Sistolik kan basıncl, mm/Hg, IQR & $130(120-141)$ & $123.5(110-135)$ & $4([-1.25]-15)$ & $<0.001 * *$ \\
\hline Diyastolik kan basıncı, mmHg, IQR & $85(81-90)$ & $82(80-85)$ & $3(0-7)$ & $<0.001 * *$ \\
\hline Açlık glukoz, mg/dl, IQR & $104(95-123)$ & $106(96-115)$ & $3([-5.25]-10.25)$ & $0.130 * *$ \\
\hline Açlık insülin, $\mu \mathrm{U} / \mathrm{mL}$, IQR & $17.68(12.47-22.52)$ & $8.3(5.63-9.81)$ & $8.88(5.16-14.82)$ & $<0.001 * *$ \\
\hline HOMA-IR, IQR & $4.52(3.26-6.32)$ & $1.96(1.44-2.96)$ & $2.16(1.37-4.29)$ & $<0.001 * *$ \\
\hline HBA1c, \%, IQR & 6.65 (6.41-7.08) & $5.88(5.53-6.14)$ & $0.84(0.44-1.25)$ & $<0.001 * *$ \\
\hline AST, U/L, IQR & $48(37-56)$ & $46(42-52)$ & $1([-5.5]-13)$ & $0.112^{* *}$ \\
\hline $\mathrm{ALT}, \mathrm{U} / \mathrm{L}, \mathrm{IQR}$ & $55(46-62)$ & $49(45-55)$ & $4([-6.5]-10.25)$ & $<0.05^{* *}$ \\
\hline Trigliserit, mg/dL, IQR & $278(245-315)$ & $189(161-246)$ & $100(20-120)$ & $<0.001 * *$ \\
\hline LDL, mg/dL, IQR & $156(143-174)$ & 135 (123-149) & $20(10-41)$ & $<0.001 * *$ \\
\hline $\mathrm{HDL}, \mathrm{mg} / \mathrm{dL}, \mathrm{SD}$ & $47.38(7.7)$ & $48.86(7.95)$ & $-1.48(10.8)$ & $0.300 *$ \\
\hline
\end{tabular}

Kısaltmalar = IQR: Interquartil range (çeyreklerarası aralık), SD: Standart deviasyon, VKI: Vücut-kitle indeksi, HOMA-IR: Homeostatic Model Assessment for Insulin Resistance (İnsülin direnci için homeostatik model değerlendirmesi), HBA1c:Hemoglobin A1c, AST: Aspartat Aminotransferaz, ALT: Alanin Aminotransferaz, LDL: Low-density lipoprotein (Düşük yoğunluklu lipoprotein), HDL: High-density lipoprotein (Yüksek yoğunluklu lipoprotein)

Normal dağılan değisşkenler SD olarak, normal dağılıma uymayan değişkenler IQR olarak belirtildi.

*Paired Sample T-Test kullanıldı. ** Wilcoxon signed-rank test kullanıldı. $p<0.05$ : Ístatiksel olarak anlamlı (kalın gösterildi)

Üç aylık kilo kayıpları başlangıca göre \%5'in altında olan (grup 1, $\mathrm{n}=13$ ), \%5-10 olan (grup $2, \mathrm{n}=24$ ) ve $\geq \% 10^{\prime}$ dan fazla olan (grup $3, \mathrm{n}=$ 21) olarak gruplandırıldı. Bel çevresi, sistolik ve diyastolik kan basıncl, açlık insülin düzeyi, HOMA-IR, HBA1c, AST, ALT, trigliserit ve LDL düzeyi; grup 3' te üç ay sonunda en fazla azalış göstermişti. Tedavi öncesi kilo, VKİ, bel çevresi, açlık insülin, HOMA-IR, AST, ALT, LDL ve HDL düzeyi; grup 3' te en yüksekti. Gruplara ait klinik bilgiler Tablo 2' de gösterilmiştir.

\%10 ve üstü kilo kaybını tedavi öncesi bağımsız olarak öngörebilmek için tedavi öncesi VKİ, bel çevresi, sistolik ve diyastolik kan basıncı, açlık glukoz, açlık insülin, HOMA-IR, HBA1c, trigliserit, LDL, HDL, AST, ALT, cinsiyet ve yaş ile univaryant ve multivaryant logistik regresyon analizi oluşturuldu. Univaryant logistik regresyon analizinde açlık insülin düzeyi, HOMA-IR ve HBA1c düzeyi anlamlı bulundu. Multivaryant logistik regresyon analizinde ise sadece tedavi öncesi HBA1c düzeyi anlamlı olarak bulundu (Odds ratio $=5.2$ [\%95 Güven aralığ 1.03-26.15], $\mathrm{p}<0.05$ ) (Tablo 3). 
Tablo II: Kilo kaybı oranlarına göre hastaların kategorize edilip bazal antropometrik ve klinik parameterler ile üç ay sonraki değişimlerinin karşılaştırılması

\begin{tabular}{|c|c|c|c|}
\hline Parametreler & $\begin{array}{l}\text { Grup } 1 \\
<\% \text { kilo kaybı } \\
(\mathrm{n}=13)\end{array}$ & \begin{tabular}{|l} 
Grup 2 \\
$\% 5-10$ kilo kaybı \\
$(\mathrm{n}=24)$
\end{tabular} & $\begin{array}{l}\text { Grup } 3 \\
>\% 10 \text { kilo kaybi } \\
(\mathrm{n}=21)\end{array}$ \\
\hline Yaș, yll, SD & $38(7.63)$ & $36(8.65)$ & $38(6.87)$ \\
\hline Boy, $\mathrm{m}, \mathrm{SD}$ & $1.57(0.06)$ & $1.56(0.09)$ & $1.6(0.1)$ \\
\hline Bazal kilo, kg, SD & $111(15.45)$ & $108(12.13)$ & $117(11.55)$ \\
\hline Kilo değișimi. kg, SD & $3.46(1.56)$ & $8.29(1.7)$ & $13.71(1.58)$ \\
\hline Bazal VKİ, kg/m², SD & $44.71(6.28)$ & $44.03(4.18)$ & $45.52(6.96)$ \\
\hline VKI değişimi, $\mathrm{kg} / \mathrm{m}^{2}$, SD & $1.39(0.64)$ & $3.39(0.7)$ & $5.32(0.67)$ \\
\hline Bazal bel çevresi, cm, IQR & $119(13.55)$ & $116(13.96)$ & $124(8.69)$ \\
\hline Bel çevresi değişimi, cm, IQR & $1(0-3)$ & $4(2-7)$ & $11(9.5-11.5)$ \\
\hline Bazal sistolik kan basıncı, mm/Hg, SD & $131(15.98)$ & $131(12.38)$ & $126(12.8)$ \\
\hline Sistolik kan basıncı değişimi, mm/Hg, SD & $1.69(3.63)$ & $3.08(7.93)$ & $14.33(12.05)$ \\
\hline Bazal diyastolik kan basıncı, $\mathrm{mmHg}$, SD & $86(5.88)$ & $84(5.6)$ & $87(4.34)$ \\
\hline Diyastolik kan basıncı değişimi, mm/Hg, SD & $2.07(3.72)$ & $3.2(6.01)$ & $3.66(4.83)$ \\
\hline Bazal açlık plazma glukozu, mg/dL, IQR & $98(92-119)$ & $113(95-125)$ & $105(91-127)$ \\
\hline Açlık glukoz değişim, mg/dL, IQR & $4([-8]-12.5)$ & $3([-7]-9.75)$ & $2([-4.5]-12.5)$ \\
\hline Bazal açlık insülin, $\mu \mathrm{U} / \mathrm{mL}$, SD & $15.44(5.64)$ & $17.76(6.5)$ & $24.72(14.52)$ \\
\hline Açllk insülin değişim, $\mu \mathrm{U} / \mathrm{mL}$, SD & $8.4(4.36)$ & 7.85 (5.99) & $17.14(13.29)$ \\
\hline Bazal HOMA-IR, IQR & $3.39(2.64-5.63)$ & $4.52(3.55-6.19)$ & $5.22(3.68-8.02)$ \\
\hline HOMA-IR değişimi, IQR & $1.8(1.21-3.17)$ & $2.06(1.16-3.15)$ & $3.03(1.89-5.87)$ \\
\hline Bazal HBA1c, \%, SD & $6.46(0.37)$ & $6.65(0.53)$ & $7.14(0.74)$ \\
\hline HBA1c değiş̧im, \%, SD & $0.65(0.44)$ & $0.68(0.32)$ & $1.23(0.5)$ \\
\hline Bazal AST, U/L, SD & $51(18.9)$ & 48 (14.03) & $53(19.34)$ \\
\hline AST değişimi, U/L, SD & $6.2(17.9)$ & 2.25 (14.49) & $5.33(17.37)$ \\
\hline Bazal ALT, U/L, SD & 54 (19.98) & $54(12.11)$ & $61(20.35)$ \\
\hline ALT değişimi, U/L, SD & $1.69(16.9)$ & $4.16(11.19)$ & $11.09(19.23)$ \\
\hline Bazal Trigliserit, mg/dL, SD & 289 (73.69) & $298(143.48)$ & 277 (75.91) \\
\hline Trigliserit değișim, mg/dL, SD & $84(66.65)$ & $65(128.47)$ & 96 (54.49) \\
\hline Bazal LDL, mg/dL, SD & $154(25.62)$ & $157(23.06)$ & $161(17.54)$ \\
\hline LDL değișimi, mg/dL, SD & 19 (17.32) & $18(25.65)$ & 35 (28.08) \\
\hline Bazal HDL, mg/dL, SD & $45(7.47)$ & $47(7.16)$ & $48(8.55)$ \\
\hline HDL değişim, mg/dL, SD & $-3.61(12.3)$ & $-1.04(9.98)$ & $-0.66(11.11)$ \\
\hline
\end{tabular}

Kisaltmalar = IQR: Interquartil range (çeyreklerarası arallk). SD: Standart deviasyon. VKI: Vücut-kitle indeksi. HOMA-IR: Homeostatic Model Assessment for Insulin Resistance (İnsülin direnci için homeostatik model değerlendirmesi). HBA1c: Hemoglobin A1c. AST: Aspartat Aminotransferaz. ALT: Alanin Aminotransferaz. LDL: Low-density lipoprotein (Düşük yoğunluklu lipoprotein). HDL: High-density lipoprotein (Yüksek yoğunluklu lipoprotein).

Normal dağılan değişkenler SD olarak, normal dağılıma uymayan değişkenler IQR olarak belirtildi. 
Tablo III: Başlangıca göre $\geq \% 10$ kilo kaybını öngörebilmek için bazal klinik ve laboratuar parametreleri ile univaryant ve multivaryant analiz oluşturulması

\begin{tabular}{|c|c|c|c|c|}
\hline & Univaryant & & Multivaryant & \\
\hline 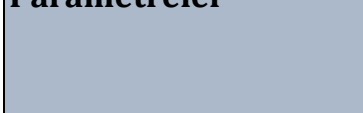 & $\begin{array}{l}\text { Odds ratio } \\
\text { (\%95 Güven aralığı) }\end{array}$ & $p$ değeri & $\begin{array}{l}\text { Odds ratio } \\
\text { (\%95 Güven aralığı) }\end{array}$ & $p$ değeri \\
\hline Yaş, yıl & $1.02(0.95-1.1)$ & 0.433 & $1.02(0.92-1.13)$ & 0.699 \\
\hline Cinsiyet (erkek) & $4.12(1.03-16.37)$ & $<0.05$ & $0.49(0.01-12.85)$ & 0.602 \\
\hline Bel çevresi, cm & $1.04(1-1.1)$ & $<0.05$ & $1.05(0.94-1.18)$ & 0.212 \\
\hline VKİ, $\mathrm{kg} / \mathrm{m}^{2}$ & $1.03(0.94-1.14)$ & 0.424 & $0.8(0.56-1.13)$ & 0.140 \\
\hline $\begin{array}{l}\text { Sistolik kan basıncl, } \\
\mathrm{mm} / \mathrm{Hg}\end{array}$ & $0.97(0.93-1.01)$ & 0.208 & $0.94(0.89-1)$ & 0.084 \\
\hline $\begin{array}{l}\text { Diyastolik kan basıncl, } \\
\mathrm{mm} / \mathrm{Hg}\end{array}$ & $1.07(0.96-1.19)$ & 0.205 & $1.21(1-1.47)$ & 0.061 \\
\hline Açlık glukozu, mg/dl & $1(0.98-1.02)$ & 0.813 & $0.99(0.95-1.03)$ & 0.232 \\
\hline Açlık insülin, $\mu \mathrm{U} / \mathrm{mL}$ & $1.08(1.01-1.16)$ & $<0.05$ & $1.09(0.93-1.27)$ & 0.070 \\
\hline HOMA-IR & $1.21(1-1.48)$ & $<0.05$ & $0.32(0.82-1.29)$ & 0.110 \\
\hline HBA1c, \% & $4.86(1.62-14.56)$ & 0.005 & $5.2(1.03-26.15)$ & $<0.05$ \\
\hline AST, U/L & $1.01(0.98-1.04)$ & 0.400 & $0.96(0.9-1.04)$ & 0.340 \\
\hline ALT, U/L & $1.02(0.99-1.05)$ & 0.140 & $1.04(0.97-1.12)$ & 0.230 \\
\hline Trigliserit, mg/dL & $0.99(0.99-1)$ & 0.537 & $0.99(0.98-1)$ & 0.547 \\
\hline $\mathrm{LDL}, \mathrm{mg} / \mathrm{dL}$ & $1.01(0.98-1.03)$ & 0.377 & $1.01(0.97-1.05)$ & 0.414 \\
\hline $\mathrm{HDL}, \mathrm{mg} / \mathrm{dL}$ & $1.03(0.96-1.11)$ & 0.342 & $1.03(0.92-1.15)$ & 0.618 \\
\hline
\end{tabular}

KIsaltmalar = VKI: Vücut-kitle indeksi. HOMA-IR: Homeostatic Model Assessment for Insulin Resistance (İnsülin direnci için homeostatik model değerlendirmesi). HBA1c: Hemoglobin A1c. AST: Aspartat Aminotransferaz. ALT: Alanin Aminotransferaz. LDL: Low-density lipoprotein (Düşük yoğunluklu lipoprotein). HDL: High-density lipoprotein (Yüksek yoğunluklu lipoprotein).

Kalın ile belirtilen değerler, istatiksel olarak anlamlı bulundu.

Gruplara ait bazal HBA1c düzeyi, Şekil 2' de gösterilmiştir. Üç aylık kilo değişimi ile bazal HBA1c düzeyi arasında Spearman korelasyon analizine göre pozitif yönde anlamlı korelasyon saptand $($ rho $=0.468, \mathrm{p}<0.001)$ (Şekil 3). 


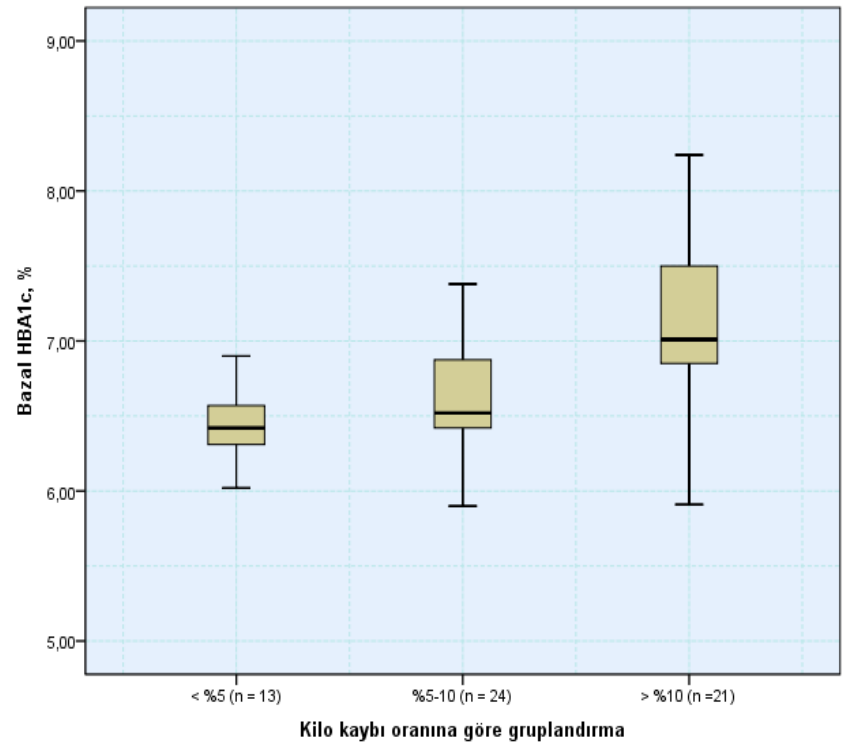

Ortadaki kalın çizgi medyan değeri, üst ve alt kutu çizgileri birinci ve üçüncü çeyrekleri gösterir.

Şekil 2. Kilo kaybı oranlarına göre gruplandırılan hastaların tedavi öncesi HBA1c düzeyinin kutu grafiği

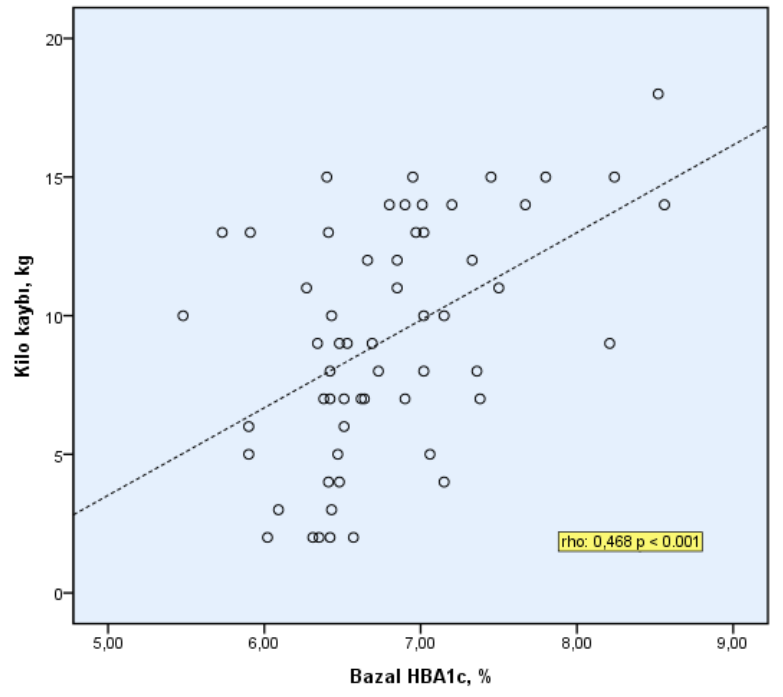

Şekil 3. Üç ayın sonundaki kilo kaybı değişim miktarı $(\mathrm{kg})$ ile tedavi öncesi HBA1c düzeyinin korelasyon grafiği

\section{TARTIŞMA}

Obezite, artan sağlık problemleri ve toplumsal maliyetlerle ilişkili olan önemli bir halk sağlığı sorunudur. Hastalığın prevalansı, özellikle düşük ve orta gelirli ülkeler olmak üzere, dünya çapında sürekli olarak artmaktadır ${ }^{12}$. Obezitenin tedavisi, komorbiditeleri ve ilgili maliyetleri azaltmak ve hastaların yaşam kalitesini arttırmak için çok önemlidir. VKI $\geq 40$ $\mathrm{kg} / \mathrm{m}^{2}$ olanlar yüksek risk kategorisinde olup en agresif tedavi yöntemlerinin uygulanması (yoğun, çok bileşenli davranışsal müdahale, farmakolojik tedavi, bariatrik cerrahi) gereken gruptur ${ }^{13}$.

Endokrin derneği klinik uygulama rehberinde, üç ay sonunda \%5'ten fazla kilo kaybı, obezite yönetimin başarılı olduğu ve tedavinin devam edilmesi gerektiği önerilmektedir ${ }^{14}$. Farmakolojik tedaviyi plasebo ile karşılaştıran çalışmalarda, hem ilaç hem de davranışsal müdahale kullanılarak yüzde 5 ila 10 kilo kaybı çok iyi bir yanıt olarak kabul edilir ve yüzde 10 'u aşan kilo kaybı ise mükemmel bir yanıt olarak kabul edilir ${ }^{3}$. Çalışmamızda literatür önerilerine uygun olarak morbid obez hastalara, yoğun yaşam tarzı değişikliği ile birlikte farmakolojik tedavi yöntemini uygulamıştık. Üç ay sonunda hastalarımızın \%77 gibi büyük bir çoğunluğunda \%5' ten fazla bir kilo kaybı sağlanmıştı. \%10' u aşan kilo kaybı gerçekleşen hasta oranı ise \%36 bulunmuştu.

Çalışmamız üç ay gibi kısa süre içinde gerçekleşmesine rağmen yaşam tarzı değişikliği ile birlikte farmakolojik tedavinin etkili kilo kaybı sağlanması için ne kadar önemli olduğunu göstermiş oldu. Gerek çevre baskısı gerekse obeziteye bağlı sağlık problemlerinden ötürü hastaların kısa zamanda kilolardan kurtulmak istemeleri günümüzde gittikçe popülerleşen bariatrik cerrahi yöntemlerine ilgiyi arttırmaktadır. Bu çalışma bariatrik cerrahiye gerek kalmadan etkili kilo kaybının kısa zamanda farmakolojik tedavi yöntemleri ile de başarılabileceğini göstermiş oldu.

Literatürde yapılan birçok randomize kontrollü çalışmaların sonucunda, yaşam tarzı değişikliği ve farmakolojik tedavi uygulanmasıyla birlikte obezitede sağlanan kilo kaybı, insülin direnci seviyelerinde azalma, kan basincl, lipid profilleri ve tip 2 diyabet insidansında azalma 
gibi çeşitli metabolik faydalarının olduğunu göstermiş ve diyabetli obez bireylerde etkili glisemik kontrol ile de ilișkili bulunmuștur ${ }^{7,15-}$ 19. Çalışmamızda da kilo kaybı ile birlikte bel çevresi, kan basıncı değerleri, glukoz ve lipit profili olumlu yönde etkilenmişti. Çalışmamız, ayrıca obezite ile ilişkili diyabetes mellitus, dislipidemi, hipertansiyon gibi metabolik hastalıkların etkili kilo kaybı ile önlenebileceğini de gösterdi.

Obezite, başta psikososyal ve genetik faktörler olmak üzere karmaşık birçok mekanizmanın etkisinde olduğundan, kilo kaybını öngörebilecek faktörleri kestirebilmek oldukça zordur. Çalışmamızın da ana konusu olan kilo kaybını öngörebilecek antropometrik ve metabolik faktörlerin belirlenmesinde sadece bazal HBA1c düzeyinin, kilo kaybını öngörebileceğini saptadık. Obezite artmış insülin direnci ve hiperinsülinemi ile ilişkilidir ${ }^{20}$ İnsülin direnci ve hiperinsülineminin şiddetine bağlı obez bireylerde kilo alımı ve bel çevresinin de artış göstermesi olasıdır. Bunlara bağlı olarak obezlerde HBA1c düzeyi daha yüksektir. Artık günümüzde HBA1c düzeyinin nondiyabetiklerde metabolik sendromun bir parçası olduğu da varsayılmaktadır ${ }^{21}$. Çalışmamızda en yüksek hiperinsülinemi ve insülin direnci olan grupta VKİ daha yüksekti, farmakolojik tedaviden sonra en fazla kilo kaybı da bu grupta oluşmuştu. Bu sonuç, obezitede hiperinsülinemi ve insülin direncinin önemli bir rol oynadığını göstermektedir. Farmakolojik tedavi sonrasında ise hiperinsülinemi ve insülin direncinin düzelmesi ile birlikte en fazla kilo kaybının bu grupta olmasına neden olmuş olabilir. Fakat kilo kaybını öngörmede insülin direnci, HOMA-IR, bel çevresi ve VKİ düzeyi anlamlı bulunmamıştı. Sadece bazal HBA1c düzeyinin kilo kaybını öngörmüş olması, açlık ve tokluk düzeylerinden etkilenmemesine dayanarak; bazal HBA1c düzeyi morbid obezitede kilo kaybını öngören prediktif bir marker olabilir.

Çalışmamızın bazı kısıtlıkları da mevcuttu. Birincisi, obezite tedavisinin temelinde uzun süreli kalıcı kilo kaybının sağlanması temel hedef olduğundan üç aylık zaman dilimi çalışma için kısa bir zaman dilimiydi. Hastaların üç aydan sonraki takip parametrelerinde eksiklik olduğundan uzun süreli takiplerine ulaşamamıştık. İkincisi, kilo kaybı; kilo kaybına bağlı enerji harcamalarındaki değişiklikler ve kilo alımını destekleyen iştahın hormonal aracıları ile genetik ve çevresel faktörler de dahil olmak üzere karmaşık birçok faktör tarafından kontrol edilmektedir. Çalışmamızda bu bireysel faktörlerin etkisi gözardı edilmişti. Üçüncüsü, çalışmamıza VKI $\geq 40 \mathrm{~kg} / \mathrm{m}^{2}$ olan morbid obezler dahil edildiğinden VKI $<40$ $\mathrm{kg} / \mathrm{m}^{2}$ olan obezlerin değerlendirilmesi yapılamamıştı. Dördüncüsü, çalışmamız retrospesifik olarak yapılmıştı. Bu konu ile ilgili prospektif olarak yapılacak çalıșmalara ihtiyaç vardır. İleride yapılacak prospektif çalışmalar ile bu konuyla ilgili daha aydınlatıcı bilgiler elde edilebilir. Son olarak ta çalışmamız tek merkez verileri üzerinden kısitlı hasta sayısı ile yapılmıștı. Çok merkezli geniş hasta katılımlı çalışmalar ile daha önemli sonuçlar elde edilebilir. Tüm bu kısitllıklara rağmen çalışmamızın ileride yapılacak bilimsel araştırmalara önemli katkılar sunacağını umuyoruz.

\section{SONUÇ}

Morbid obezitede, kilo kaybı için bariyatrik cerrahi yöntemlere gerek kalmadan yaşam tarzı değişikliği ve etkili farmakolojik tedavi ile de kilo kaybı ve komorbid durumların düzeltilmesi olasıdır. Kısa süreli cerrahi dışı kilo kaybını öngörebilmek için başlangıç HBA1c düzeyi prediktif bir marker olabilir.

Etik Kurul Kararı: Çalışmamıza lokal etik komite tarafından onay verilmiştir (karar no: 2021/2794). 
Çıkar Çatışması Beyanı: Yazarlar çıkar çatışması olmadığını bildirmişlerdir.

Finansal Destek: Bu çalışma her hangi bir fon tarafından desteklenmemiştir.

Declaration of Conflicting Interests: The authors declare that they have no conflict of interest.

Financial Disclosure: No financial support was received.

\section{KAYNAKLAR}

1. Satman I, Omer B, Tutuncu Y, et al. Twelve-year trends in the prevalence and risk factors of diabetes and prediabetes in Turkish adults. Eur J Epidemiol. 2013; 2: 169-80.

2. Wing RR, Lang $W$, Wadden TA, et al. Benefits of modest weight loss in improving cardiovascular risk factors in overweight and obese individuals with type 2 diabetes. Diabetes Care. 2011; 7: 1481-6.

3. Perreault L, Apovian C. Obesity in adults: Overview of management. In: UpToDate, Pi-Sunyer FX, Seres D (Ed), UpToDate, Kunins L. ( Accessed on April 28, 2020)

4. Durrer Schutz D, Busetto L, Dicker D, et al.: European Practical and Patient-Centred Guidelines for Adult Obesity Management in Primary Care. Obes Facts. 2019; 12: 40-66.

5. Tamura BK, Bell CL, Masaki KH, Amella EJ. Factors associated with weight loss, low BMI, and malnutrition among nursing home patients: a systematic review of the literature. J Am Med Dir Assoc. 2013; 9: 649-55.

6. Apolzan JW, Venditti EM, Edelstein SL, et al. LongTerm Weight Loss With Metformin or Lifestyle Intervention in the Diabetes Prevention Program Outcomes Study. Ann Intern Med. 2019; 10: 682-90.

7. Dombrowski SU, Knittle K, Avenell A, AraújoSoares V, Sniehotta FF. Long term maintenance of weight loss with non-surgical interventions in obese adults: systematic review and meta-analyses of randomised controlled trials. BMJ. 2014; 348: 26-46.

8. Tang Q, Li X, Song P, Xu L. Optimal cut-off values for the homeostasis model assessment of insulin resistance (HOMA-IR) and pre-diabetes screening:
Developments in research and prospects for the future. Drug Discov Ther. 2015; 6: 380-5.

9. Yumuk V, Tsigos C, Fried M, et al. European Guidelines for Obesity Management in Adults. Obes Facts. 2015; 6: 402-24.

10. Garvey WT, Mechanick JI, Brett EM, et al. American Association of Clinical Endocrinologists and American College of Endocrinology Comprehensive Clinıcal Practıce Guidelınes For Medical Care of Patients With Obesity. Endocr Pract. 2016; 22: 1-203.

11. US Food and Drug Administration. FDAapproved drug products: Contrave. 2014. http://www.accessdata.fda.gov/drugsatfda_docs/la bel/2014/200063s000lbl.pdf. Accessed April 26, 2016.

12. NCD Risk Factor Collaboration (NCD-RisC). Worldwide trends in body-mass index, underweight, overweight, and obesity from 1975 to 2016: a pooled analysis of 2416 population-based measurement studies in 128.9 million children, adolescents, and adults. Lancet. 2017; 390: 2627-42.

13. Bray GA, Kim KK, Wilding JPH; World Obesity Federation. Obesity: a chronic relapsing progressive disease process. A position statement of the World Obesity Federation. Obes Rev. 2017; 7: 715-23.

14. Apovian CM, Aronne LJ, Bessesen DH, et al. Pharmacological management of obesity: an endocrine Society clinical practice guideline [published correction appears in J Clin Endocrinol Metab. J Clin Endocrinol Metab. 2015; 2: 342-62.

15. Kılınç F, Alpağat G, Demircan F, et al. Clinical and laboratory characteristics of exenatide-given patients in endocrinology clinic of a university hospital. Dicle Tıp Dergisi. 2014; 1: 128-32.

16. Erdem H, Aziret M, Çetinkünar S, et al . Effects of Intragastric Balloon on Body Mass Index, Lipid Profile and Blood Glucose Regulation: A Prospective Study. Dicle Tip Dergisi. 2016; 1: 22-6.

17. Johansen MY, MacDonald CS, Hansen KB, et al. Effect of an Intensive Lifestyle Intervention on Glycemic Control in Patients With Type 2 Diabetes: A Randomized Clinical Trial. JAMA. 2017; 7: 637-46.

18. Aucott L, Gray D, Rothnie H, Thapa M, Waweru C. Effects of lifestyle interventions and long-term 
weight loss on lipid outcomes - a systematic review. Obes Rev. 2011; 5: 412-25.

19. Ceylan, Ş. D., Ceylan, Ş. A., Fatih E. K. E. R., \& Güngüneș, A. Morbid obez hastalarda kilo kaybının insulin direnci, bazal metabolizma hızı, antropometrik ölçümler ve tiroid fonksiyonlarına etkisi. Anadolu Güncel Tıp Dergisi. 2019; 4: 99-104.

20. Hulman A, Simmons RK, Brunner EJ, et al. Trajectories of glycaemia, insulin sensitivity and insulin secretion in South Asian and white individuals before diagnosis of type 2 diabetes: a longitudinal analysis from the Whitehall II cohort study. Diabetologia. 2017; 7: 1252-60.

21. Annani-Akollor ME, Laing EF, Osei $\mathrm{H}$, et al. Prevalence of metabolic syndrome and the comparison of fasting plasma glucose and HbA1c as the glycemic criterion for MetS definition in nondiabetic population in Ghana. Diabetol Metab Syndr. 2019; 11: 26. 